\section{Evolution and optimization}

SIR-Joe Felsenstein opens his review' of Sewall Wright's biography by W.B. Provine $^{2}$ in these words: "Evolutionary theory in the 1960 s and 1970 s was dominated by optimization, by the search for the quantity evolution would maximize. The mean fitness of a population was not precisely what natural selection would maximize in a Mendelian genetic system, so perhaps if we did enough theory we could find out what was. The picture hanging on our wall was of R.A. Fisher, who had emphasized the importance of natural selection in large populations."

This might be taken to imply that Fisher engaged in the search to which Felsenstein refers, as many seem to think. This is not the case; indeed, his students from the late 1950 s (I write as one of them) were taught not to think in such terms, and we developed a marked scepticism towards those many who did. As early as 1941, Fisher ${ }^{3}$ railed against any such optimization: "Wright's conception ... that selective intensities are derivable, like forces in a conservative system, from a simple potential function dependent on the gene ratios of the species as a whole, has led him to extensive but untenable speculation."

\section{Foreigners in Japan}

SIR-As a British scientist temporarily in Japan participating in a programme of collaborative research sponsored by the Japanese Foundation for the Promotion of Cancer Research, I should like to add a comment to David Swinbanks' article "British are reluctant travellers" (Nature 323, 571; 1986).

It is not difficult to understand, particularly when viewing the situation from the United Kingdom, the apprehension about living and working in Japan that may be in the minds of British scientists. However, once in Japan many of the difficulties one expected to face are, in reality, much less serious than they appear from the United Kingdom. In fact, many of the so-called 'problems' are a source of real pleasure in the interest and the very challenge which they present.

The 'challenge' of Japan should be viewed in a positive way because there are so many things to be gained by spending time here. First, it should be recognized that many of the research centres and university departments in Japan are of a very high standard and have truly earned their international reputation for excellence. One can therefore realistically expect the time spent here to be scientifically productive and successful. Of course, one is expected to work hard and the normal working hours are longer than those in the United Kingdom, but this should not be a detraction. In most research groups this is
To this evidence can now be added the recently published letter ${ }^{4}$ that Fisher wrote to M. Kimura on 3 May 1956: "In considering the original statement of what I ventured to call 'the fundamental theorem of natural selection', I had, of course, considered the relation between such a situation and that in which a potential function existed, for my mathematical education lay in the field of mathematical physics.

As you realize, I preferred to develop the theory without this assumption, ... Of course I realise that Sewall Wright has often argued as though such a potential function must exist, ...."

In the matter of optimization, the picture on the wall was that of Sewall Wright, and it carried the caption "The inventor of the notion of the adaptive topography, the adaptive surface, and the fitness function". A.W.F. EDWARDS

Gonville and Caius College,

Cambridge,

CB2 1TA, UK

Felsenstein, J. Nature 324, 175-6 (1986)

2. Provine, W.B. Sewall Wright and Evolutionary Biology (University of Chicago Press, 1986).

. Fisher, R.A. Ann. Eugen. 11, 53-63 (1941).

4. J.H. Bennett (ed.) Natural Selection, Heredity, and Eugenics (Oxford Clarendon Press, 1983).

hardly noticeable as there is a strong feeling of companionship and very much a community spirit.

Second, although one might be apprehensive about the language problem and differences in culture, the Japanese are a very generous and helpful people. My colleagues here go out of their way to ensure that, as far as possible, my every need is met, and that the communication problem both inside and outside the laboratory does not lower the quality of my life here.

The concern about finding employment back home is understandable but should not be allowed to over-influence a decision to come to Japan. At a time when efforts are being made by both industry and government to increase British interactions with Japan, experience in Japanese science and Japanese culture must be an advantage. For those who wish to return to an industrial position, I suggest that they make contact with companies before departing for Japan. Certainly, the one-year fellowships that the Royal Society plans to offer to those returning to the United Kingdom should cushion the problem of finding an immediate position.

For those who are offered the opportunity of participating in research in Japan, to fail to accept it is to miss the chance of a lifetime.

\section{National Cancer Center \\ Research Institute \\ Tsukiji 5-chome,}

D.S. JONES

Tokyo, Japan
Science in Iberia

SIR-Your report on tropical research in Portugal states that "in the first major outbreak [of coffee leaf rust], towards the end of the nineteenth century, Ceylon's coffee industry was utterly destroyed" (Nature 324, 331; 1986). To be precise, British entrepreneurs began to develop coffee production in Ceylon in 1803, increasing annual production to over one million pounds within 50 years. But the first major outbreak of coffee leaf rust caused by Hemileia vastatrix occurred in 1869 , and not "towards the end of the nineteenth century". As it was one of the classic cases in the history of phytogeography of destruction of plantation monoculture by a pathogen, the record should be put straight. Ceylon has been a tea producer since the 1870 s.

In your coverage of science in Spain, you record the activities of two Spanish Nobel laureates, Ramon y Cajal (1906) and Severo Ochoa (1959). It would be fair also to mention Portugal's 1949 Nobel laureate in sciences, Antonio Egas Moniz (1874-1955) who is recognized for his pioneering work in prefrontal lobotomy and in cerebral angiography; a junior contemporary of Ramon y Cajal, the Portuguese neurosurgeon was also politically active. He served as a deputy in the Portuguese parliament from 1903 to 1917 , when he was named as ambassador to Spain and was also appointed as the Minister of Foreign Affairs. Moniz also served as the president of the Portuguese delegation at the 1918 Paris Peace Conference, before retiring from politics in the following year ${ }^{2}$

SACHI SRI Kantha Laboratory of Marine Biochemistry,

Faculty of Agriculture,

University of Tokyo,

Bunkyo-ku, Tokyo 113, Japan.

1. Mueller, W. Encyclopedia Americana vol. 7, 211a (Americana Corporation, New York, 1964)

2. Parker, S. P. (ed). McGraw-Hill Modern Scientists and En gineers vol. 2, 319 (McGraw-Hill, New York, 1980).

\section{Iberia reversed}

SIR-Perhaps it is labouring the obvious, but it seems that the cover of Nature 324, No. 6095, which depicts a Catalonian view of Iberia in 1375, was placed upside down if one subscribes to the convention that north is up. Inversion of the cover might allow more readers to appreciate correlations with modern Iberia.

University of British Columbia J.T. BEATTY Department of Microbiology, $300-6174$ University Boulevard, Vancouver, BC V6T 1W5, Canada

Many early maps were turned round in order to make the best use of the paper without altering the format of the completed atlas. - Editor, Nature. 